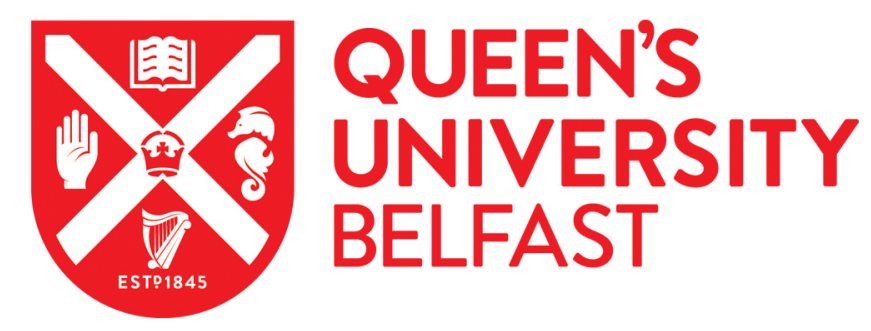

\title{
Towards a Critical Ecology of Child Development: Aligning the Theories of Bronfenbrenner and Bourdieu
}

Houston, S. (2017). Towards a Critical Ecology of Child Development: Aligning the Theories of Bronfenbrenner and Bourdieu. Families, Relationships and Societies, 6(1), 53-69.

https://doi.org/10.1332/204674315X14281321359847

Published in:

Families, Relationships and Societies

Document Version:

Peer reviewed version

Queen's University Belfast - Research Portal:

Link to publication record in Queen's University Belfast Research Portal

Publisher rights

Copyright 2015 the author.

This work is made available online in accordance with the publisher's policies. Please refer to any applicable terms of use of the publisher.

\section{General rights}

Copyright for the publications made accessible via the Queen's University Belfast Research Portal is retained by the author(s) and / or other copyright owners and it is a condition of accessing these publications that users recognise and abide by the legal requirements associated with these rights.

Take down policy

The Research Portal is Queen's institutional repository that provides access to Queen's research output. Every effort has been made to ensure that content in the Research Portal does not infringe any person's rights, or applicable UK laws. If you discover content in the Research Portal that you believe breaches copyright or violates any law, please contact openaccess@qub.ac.uk. 


\title{
Towards a Critical Ecology of Child Development in Social Work: Aligning the Theories of Bronfenbrenner and Bourdieu
}

\begin{abstract}
Bronfenbrenner's model of bio-ecological development has been utilized widely within the social sciences, in the field of human development, and in social work. Yet, while championing the rights of marginalised families and communities, Bronfenbrenner had under-theorized the role of power, agency and structure in shaping the 'person-context' interrelationship, life opportunities and social well-being. To respond to this deficit, this paper firstly outlines Bronfenbrenner's 'person, process, context, time' model. Secondly, it then seeks to loosely align aspects of Bronfenbrenner's model with Bourdieu's analytical categories of habitus, field and capital. It is argued that these latter categories enable social workers to develop a critical ecology of child development, taking account of power and the interplay between agency and structure. The implications of the alignment for child and family social work are considered in the final section.
\end{abstract}

Key words: social ecology, power, Bronfenbrenner, Bourdieu, development

\section{Introduction}

Urie Bronfenbrenner's ecological theory of child development $(1979 ; 2005)$ has made a seminal contribution to our understanding of how children and young people mature and progress in their formative years. His work has been applied in a raft of contexts and has laid a determinative foundation for social work's nascent, ecological perspective. Within the UK, it underpins the Framework for the Assessment of Children in Need (Department of Health, 2000) with its articulation of three interlocking domains covering child development, parenting capacity and the impact of family and environmental factors. Bronfenbrenner's ideas have also been embraced in a number of key social work texts that emphasize personal development within a social context (Aldgate et al, 2006; Trevithick, 2009; Horwath, 2010; Sudbery, 2010). Moreover, his ecological framework has been widely cited and appropriated within areas such as family support to children 'in need' (Jack, 2000; Hardy and Darlington, 2008; Branch et al., 2013); the assessment of children and families (Serbati et al., 2013); the theorization of resilience, trauma and attachment (Harney, 2007); and the empirical investigation of familial relationships (Tudge et al., 2009). In all of this, 'Bronfenbrenner sought to sort out and explicate the common principles of both ecology and system's thinking in a manner having application across various social scientific disciplines' (Besthorn, p. 175, 2013).

Within the social work literature, however, less emphasis has been given to a critical examination of Bronfenbrenner's theory, addressing its strengths and weaknesses, and attempting to ameliorate the latter by drawing on complementary, theoretical sources. More specifically, Bronfenbrenner's conceptual framework has not been systematically 
reviewed by the social work academy from the standpoint of critical social theories that address the role of power and social structure in shaping human development, agency and social systems. In this paper, I respond to this gap by explicating Bronfenbrenner's core ideas and principles as found in his 'person, process, context and time (ppct)' formulation (2005). The strengths and weaknesses of this conceptualization are then reviewed. At this point, an argument is made for aligning certain aspects of Pierre Bourdieu's (2003) social theory of agency and structure with the 'ppct' model, as a way of complementing, extending and building on it. I finally look at the implications of the alignment for child and family social work.

At this point, it is important to register that, at first glance, Bourdieu's starting point is notably different to that of Bronfenbrenner's. The former attempted to articulate a theory which illuminated the analytical relationship between agency and structure: a central preoccupation in sociology and social theory. This can be contrasted with Bronfenbrenner's oeuvre which focused on the psycho-social determinants of optimal child development even though he was passionately interested in social justice. Yet, at a general level, both theorists acknowledged the importance of (a differentiated) social context in shaping human practices, social outcomes, and the person's consciousness. While their linguistic and conceptual configuration of this social context was different, it is contended that there are some convergences between the two theories which allow for their mutual enrichment. In particular, Bourdieu brings a sophisticated battery of concatenated, analytical constructs to any inquiry into human development. Importantly, what is being proposed in not a synthesis between the two theories given their different epistemological orientations, but rather a pragmatic alignment which enables a much broader perspective to emerge on how and why children either meet, or fail to meet, expected developmental outcomes in a social world beset with enabling and constraining social structures, asymmetrical relations of power, and unequal access to resources. This endeavour recognizes the importance of building conceptual bridges in social work theorizing, amalgamating the strengths of diverse sources of knowledge.

\section{Bronfenbrenner's Model of Human Development}

In this section, I will primarily cover Bronfenbrenner's later work (2005) on a bio-ecological understanding of human development. However, prior to reaching this mature position, his early, iconic treatise - as set out in The Ecology of Human Development (1979) - had principally emphasized the pivotal role of the social context surrounding the individual. As his thinking progressed, through self-reflection and self-critique, the focus on context was enlarged to embrace a much deeper understanding of the person, and how factors within innate constitution could impact on development throughout the life-course. This was explicated in his 'ppct' model and is summarized below (see Figure 1).

\section{PLACE FIGURE 1 HERE}


The person, for Bronfenbrenner, embodies a multiplicity of biological and genetic mechanisms that commingle to produce effects on behaviour and development (2005). For example, children are born with distinct temperaments: some are shy and sensitive, others extrovert, while another cohort are 'hard to warm up'. In addition, he or she presents to the social world with three types of characteristic, namely: (i) demand characteristics; (ii) resource characteristics; and (iii) force characteristics. Demand characteristics refer to those immediately obvious and visible markers defining our being. Significantly, they influence another person's reactions to and expectations of us. For instance, my age, gender, race or disability can dramatically impact on the way another responds to me in terms of his demands. Resource characteristics, by way of contrast, are not outwardly visible but rather refer to internal mental, emotional and cognitive dispositions within the person. So, the way a person constructs the world cognitively, will impact on how she deals with various different situations. Clearly, such dispositions can be a positive resource for re-framing challenging life events, like stress, or a barrier to meaningful change if the person's cognitive set is imbued with pessimism. Resource characteristics also embrace an individual's access to social and material assets including the provision of good housing, nourishment, educational achievement and strong attachments to significant others. Lastly, force characteristics are reflected in the person's inner drive, capacity for resilience, internal motivation, and sense of self-efficacy. One child might be resolute in the achievement of her goals while another gives up easily. The first is rich in force characteristics, the latter lacking in these attributes.

\section{Process}

By process, Bronfenbrenner is concerned with two types of interaction: one with an object and a second with another person. Taking the former, a child may engage in meaningful play with a range of toys in a nursery. This activity stimulates the child's cognitive development and motor skills. Or, an adolescent loses a sense of self when playing a guitar. This activity gets the young person into the 'zone' and, in doing so, develops skills that can be recognized by others. In respect of the latter process, human development is predicated on social interaction with significant others. Through social interaction, we develop our sense of self, learn to role-take with others, develop skills of empathy and problem-solving and form and sustain intimate relations. Impoverished interaction, by way of contrast, leads to care and control problems, tarnished identities, insecurity and can eventuate in negative chain reactions with deleterious outcomes for the young person.

\section{Context}

Under this heading, Bronfenbrenner set out his now famous and time-honoured, description of the various imbricated systems shaping child development (see Figure 2 ). He listed them as the 'micro', 'meso', 'exo' and 'macro' systems. When combined, they formed 
a tessellated configuration of ever increasing spheres of social influence much like a grouping of nested Russian dolls.

\section{PLACE FIGURE 2 HERE}

The micro-system captures the arena where the child spends most of her time in intimate, face-to-face interactions with significant others such as the family or peer group. It is here that attachments or strong bonds are formed, a secure base realised and identity is moulded. The micro system is also the place where socialization takes place and with it, moral development. The converse of this idealized picture might instead be the case. Thus, micro-systems can be typified by disrupted attachment, poor socialization, unpredictable home environments and domestic violence.

The meso-system charts the combined influence of each of the child's micro-systems on her development. What is more, it represents those activities and roles that overlap across the range of micro-systems. Hence, a young person maybe involved in a church choir along with a number of his peer-group. It is this rich soup of interaction that provides stimulation, structure, purposive action and meaning. One's narrative - or the story I tell about myself takes hold through the daily concourse of the meso-system: its rich multiple linkages. Yet again, the meso-system might signify weak or tenuous relationships or even an absence of connection. Even where solid connections exist, they may be typified by criticism.

The exo-system has more of an indirect influence on developmental well-being, according to Bronfenbrenner. The person may not be a part of this system but nevertheless is affected by its influence. A parent who is made unemployed by his workplace (a part of the exo-system) becomes depressed at home and this has an understandable affect on his children. Or, reductions in neighbourhood policing (a relevant exo-system) may circumscribe opportunities for outside play. This system is therefore more distant from the subject and often takes on an institutional form that indirectly has a knock-on effect for the micro and meso-systems. Social service departments might be seen as a key part of the exo-system for service users.

The macro-system is the enveloping, overarching sphere embracing culture primarily but also the polity and economy. It is the arena where social and political policy is formed. Large-scale processes are instituted here. As an example, welfare regimes develop distinctive forms of help or recast the nature of societal concern for the most disadvantaged. How a State deals with inequality and the distribution of wealth has major ramifications for the developing child and family well-being. The macro-system, for Bronfenbrenner, has a discernable influence on life options, choices and outcomes. For him, social policy must support and resource the carer if children are to succeed in meeting their potential. 
The last aspect of Bronfenbrenner's theorem is 'time'. Earlier on, he had referred to this as the chrono-system. Not only do spatial factors affect human development, but also temporal challenges throughout the life-course and historical changes within society. Events in time change the dynamics within each of the afore-mentioned systems. People enter and exit our social milieu according to expected transitions, losses and unexpected changes. Time can also afford relative stability and continuity as we mature. Our psycho-biographies are often marked by meaningful calendar dates: birthdays, deaths and so on. The time period marked by adolescence might evince 'storm and stress' but not always.

By way of comment on the 'ppct' model, we can say that Bronfenbrenner's ideas are most helpful to social workers because they remind us that human development is primarily a social affair. While psychological theories of progression, such as lifespan psychology, (Santrock, 2009) have their place, it is to the 'social' that we must look if we are to avail of a comprehensive understanding of child development (Taylor, 2004). That is why Bronfenbrenner's approach should make 'intuitive sense to any social worker' (Sudbery, 2010 , p. 153). Moreover, the 'ppct' model provides a schematic focus for social work assessment and intervention. Social workers can map the density, thickness and vibrancy of a child's micro and meso-systems, examine their linkages, look at how and where emotional and social support is given, where it is absent, whether it is bi-directional and pinpoint low warmth, high criticism networks. More than that, they can use the model to reflect on the wider impact of the culture and political systems particularly as they are reflected in inequalities (Jack, 2000). In highlighting the significance of these social dimensions, Bronfenbrenner had not lost sight of the individual, her internal world of thought and perception and human agency. This consideration is vital, as social work looks to the interplay between the internal and external worlds.

However, even though Bronfenbrenner was very concerned with structural cleavages, and actively campaigned against them, he offered a limited theorization of power and ideology to strengthen his scholarly an advocacy endeavours. In his work, it is not clear how power permeates social life at the 'micro', 'meso', 'exo' or 'macro' levels, how it circulates within social structure in an enabling and constraining way. We need to know how individuals can use power, as a transformational resource, to achieve their aims when facing oppositional forces emanating from class, race, religion, norms, roles and routines. How power works in reproducing social stratification - is another query.

The manner in which power functions as a form of discipline and punishment in neo-liberal societies must also be perused (Foucault, 1977). In the Ecology of Human Development (1979), Bronfenbrenner does refer to power, but in a limited way that gives no substantive answers to these questions. Instead, he briefly alludes to settings of power. These are sites where certain actors, or power elites, control the allocation of resources and they can be formal (as in board meetings) or informal (as occurring in social life). Yet, how they achieve 
and maintain this status is not clear. Structural barriers to child development cannot be understood fully without comprehending coercion and conflicts of interest. Without this understanding, ecological theory is limited to an expository, rather than explanatory, account of the person-in-society. Moreover, anti-oppressive social work practice is inconceivable without a credible theory of power (Tew, 2006).

This theoretical gap also compromises Bronfenbrenner's understanding of phenomenology. Phenomenology is an approach which attempts to analyse and describe everyday life and its associated states of consciousness. To be fair, Bronfenbrenner did acknowledge this dimension and how it played a role in human development. For him, people inwardly define events or make constructions about them and this, in turn shapes their behaviour. This insight comes out in his understanding of the person referred to earlier. But again, it is not clear how power, ideology and socialization shape a person's consciousness, nor is there a consideration of the mechanisms that allow this to happen. People's perceptions are influenced by external factors such as cultural norms. Cultural norms, however, may well be shaped by powerful interest groups. We need further clarity on these points if a critical ecology of child development is to emerge. At this point, we can look to some of Pierre Bourdieu's ideas for inspiration.

\section{Bourdieu, Power and Social Ecology}

It is impossible to fully capture the rich nuances of Bourdieu's social theory within the confines of this section, so the following presentation will be have to be selective and attenuated. Essentially, Bourdieu comprehends power as a phenomenon that is generated culturally and reproduced through the constant outworking of agency and structure (1991; 2003). The debate over agency and structure concerns the relationship between the individual and wider social sphere. In effect, it reflects on how structure exerts power to determine action; and how structural constraints impact on human freedom and creativity.

For Bourdieu, the interplay between agency and structure can be illuminated through three inter-linked concepts: habitus, capital and field. Habitus is the deep-seated set of durable, internalized dispositions, propensities and predilections to think, feel, judge and act in certain pre-determined ways that we gain from societal conditioning and socialization (Bourdieu, 2003). It therefore comes about through our immersion in the social world and the power it exudes to shape our inner consciousness or meaning-making activities. Over time, a person's habitus will come to mirror social divisions within the surrounding culture. As I have said elsewhere, 'fundamental life chances are determined by our habitus because it becomes embodied in the way we speak and in our preferred tastes, proclivities and deportment' (Houston, 2002, p. 157). That said, habitus is not immutable or irrevocably deterministic as new experiences with the social context can introduce different social norms and people can exercise free will and agency over habitus - albeit to some degree. 
In terms of child ecology, habitus incontrovertibly shapes the way caregivers parent their children, their approach to child development, and the routines and rhythms within the familial domain of experience. This is because it has been conditioned over time through the media, parents' own upbringing and micro-systems, normative discourses, class allegiance and other influences in their social ecology. For instance, health and social care policy discourses convey notions of 'good enough parenting' and normative accounts of childhood development that direct parents to act in certain ways or else face the ignominy of being branded deviant (Smith, 2012).

In a related vein, Bourdieu's notion of capital refers to a person's access to or possession of a range of different types of resource (Bourdieu, 2003). These resources can be material, cultural, or social. In addition, people can claim a certain social status or occupational rank and these attributes are examples of symbolic types of capital. Being well endowed with various types of capital enhances one's power to transform or influence events, and creates opportunities to maximise personal goals and intentions. Thus, capital potentiates strategic action. Dominant classes within society are invariably privileged in the amount and type of capital they possess, giving them an advantage in the ubiquitous power plays in which they indulge, whereas subaltern ones strive to build on their meagre allocation.

Returning to the theme of social ecology, the allocation of social capital can inexorably affect a child's educational development (Connolly, 2004). In this regard, Payne (2008) surmises that neighbourhoods possessing high levels of social capital are much more likely to have better achieving schools compared to ones where social capital is thinly dispersed. What is more, children raised in families were capital is plentiful, have more access to books, reading opportunities, educational technology and extra-curricular supports. Beyond education, the allocation of capital can also affect health outcomes. This is because it promotes better access to information about health thus averting risky behaviours and parenting practices. Parents with social capital are also much more able to access support to promote their mental well-being.

Bourdieu's third concept, 'field', denotes the social and institutional arenas or networks in which actors are socially positioned. Within these arenas, a person's habitus is nurtured and embedded. Not only that, actors compete for various types of capital within the field in order to improve their positions and thus it is characterized by power differentials, struggle, contestation, and vested interests. Fields can be social, cultural, educational, religious, artistic, economic or intellectual and are invariably hierarchical. Each has its own specific logic and set of principles guiding action. The interaction between these principles, a person's habitus and access to capital, determines where she is positioned in the field.

For children and young people, the educational field takes on a particular purchase given that educational outcomes affect so many life opportunities (Fowler, 1997). Using a Bourdieusian lens, we can view it as an arena in which children are socially positioned and subject to rules defining behaviour, deportment and attitude. This arena may augur well for 
middle class children whose habitus is congruent with the school's expectations. A working class child (or child from a minority ethnic background), though, may enter this field with an alternative set of dispositions, embodiment and language code - perhaps more geared to attaining practical, rather than academic, skills. Teachers in the school may, to compound matters, reproduce the field's principles in the way they relate to the children and form judgements about their abilities and progress. In doing so, they (unintendedly) exercise power to reproduce inequality.

\section{Aligning the Ideas}

Having presented an overview of the two theories, we can now consider whether there are tentative points of contact between them (see Figure 3). This is not to suggest that there is a direct correlation between Bronfenbrenner and Bourdieu's ideas, or that their key concepts are in any way synonymous. Rather, it is to make an approximate connection within a broad family resemblance. Alternatively put, there is a loose intersection between some of the theories' concepts based on the fact that they border or verge, however hesitantly, on similar conceptual territories. Thus, this move is not about synthesis; instead, it is to make the case for pragmatic alignment in order to buttress, widen and build on Bronfenbrenner's theory - moving it in the direction of a critical ecology.

\section{PLACE FIGURE 3 HERE}

As can be seen, there are four primary interfaces between the two theories. First, it has already been noted that Bronfenbrenner's idea of the 'person' embraced an understanding of her inner world of cognition, attitudes and feelings. While this does not directly map across to Bourdieu's articulation of habitus, there is a degree of overlap between the former and latter notions. Clearly, both theorists were interested in the person's cognitive world and sought to apprehend it through a phenomenological approach. Equally, both saw this world as being shaped by social context, and processes of socialization. That said, Bronfenbrenner was more interested in how the inner world of thought and feelings influenced development. Bourdieu, alternatively, was more concerned, sociologically, with the reproduction of power and domination through habitus. Yet, this latter insight can amplify and widen one's understanding of child development by showing the mechanism through which children and parents come to internalize hegemonic, behavioural and social norms, roles and social positions.

The second interface concerns the resources at the person's disposal. Earlier, I had indicated that Bronfenbrenner asserted how a person's access to a range of material and social resources could directly affect his developmental pathway. This insight chimes with Bourdieu's understanding of capital - particularly as both theorists foregrounded the importance of educational and cultural resources in opening up life chances. Even so, capital, for Bourdieu, was much more of a loaded concept as it was linked with social class, economic ideology, and the actor's relative position in various social fields. This more 
politicized view of capital, arguably, can strengthen an ecological perspective on childhood by showing how inequitable resource allocation in neo-liberal society can stigmatize and devalue actors (Peillon, 1998) - even though it may be viewed as perfectly legitimate by those in powerful (and subordinate) positions.

A third resonance can be detected in Bronfenbrenner's idea of force characteristics and Bourdieu's notion of human agency. Both convey a sense of the actor's capacity to act independently of social constraints through intention and purpose. Moreover, both ideas are linked to available resources or capital. Hence, a parent can avail of economic resources to better her prospects and realise her goals through gaining access to employment training. However, even though there is some similarity between these conceptions, Bourdieu provides a more nuanced account of agential powers by linking them with habitus. Bourdieu reminds us that, even though habitus penetrates deeply into the human psyche, we are not mindless vehicles driven by our inner dispositions. Instead, habitus acts like a loose set of guidelines giving us (a qualified) space to strategize, adapt and improvise, as we gain a 'feel for the game'. In Bronfenbrenner's account, agency seems to be linked more to internal traits such as resilience, motivation and persistence. Once again, the Bourdieusian perspective provides a much deeper view of human power, theorizing how it is a product of the dialectic between the internal and external worlds. A young person's motivation and persistence cannot be seen only as intrinsic qualities but also a product of his social position and ingrained dispositions inculcated by social class and culture.

Lastly, we might draw a connection between Bronfenbrenner's stress on the social context and its various systems of influence, and Bourdieu's notion of the 'field'. We can find some correspondence between a young person's meso-system, his engagement in the life of his school and, from an alternative viewpoint, his participation in the educational field. Similarly, the macro-system and cultural field can be juxtaposed (to some degree). That said, the field is often a power-laden site: a site of struggle and contestation, a battleground of positioning, leverage, one-upmanship. While Bronfenbrenner's schematic portrayal of the four systems helpfully differentiates the social context, and its influence on child development, it under theorizes the role of power. In the real world, argues Bourdieu, systems are held together through hegemonic forces. What is important, here, is a young person's position within the field, what capital is afforded to him by the field, how it allows him to access (or debars him from) other fields.

\section{Implications for Child and Family Social Work}

We are now in a position to consider how the two theories can be used, in combination, by social workers when assessing a child's development. A child care assessment in social work involves a 'perceptual/ analytic process of selecting, categorising, organising and synthesising data' (Coulshed, 1988, p. 13) in order to reach an informed formulation on risk, need and resources. It seeks to gain an understanding of the problems, the people involved, the settings, and the interactional processes taking place. In particular, the assessment 
might concentrate on the three inter-linked domains outlined in the Department of Health's (2000) Assessment Framework mentioned earlier. One of these domains attends to the child's developmental needs under the categories of health, emotional expression, behaviour, identity, social presentation and self-care skills.

By applying by Bronfenbrenner's 'ppct' model', and Bourdieu's conceptual categories (of habitus, field and capital), we can gain a deeper understanding of these assessment areas and processes. Thus, when gathering information about the child and family, we can explore aspects of the person, the processes in which she is engaged, the composition of her micro, meso, exo, and macro-systems, and the effects of the temporal dimension. More than this, the family's circumstances can be viewed from a Bourdieusian lens bringing a fresh perspective on power, showing how development is constrained by wider social structure. Hence, the synergistic connections between these two sources, as depicted in Figure 3, can add an analytical purchase to the assessment as they combine insights from social ecology with critical perspectives on agency, power and structure. The central importance of analysis in assessment is taken up by Turney et al. (2012). They argue from the research evidence that effective child and family assessment 'needs to move beyond the simple collection of information (that is, a record of what happened) to a consideration of why...it requires the social worker to understand and analyse the information' (p. 101). Such analysis can be enhanced by applying theoretical frameworks (Brandon et al., 2008); different types of reason (rational and intuitive) (Reder and Duncan, 2004; Munro, 2010); and reflective evaluation (Holland, 2010).

In a related vein, the 'ppct' model can throw light on the nature of a child's cognitive and emotional characteristics. It might help us to understand what sense a child has made of significant life events (for instance, loss, change, disruption, trauma, broken attachment) and transitions in the life-cycle (for example, the first day at school, entering adolescence, leaving home). We are trying, here, to apprehend dominant patterns in thought, cognitions, narratives and emotional reactions as a way of forming an impression of the inner world of that child. The way she construes herself, others and the social world will have manifold implications for the way she acts: this is a key phenomenological supposition. In all of this, 'keeping the child or young person 'in view' is fundamental to good assessment' (Turney et al., 2012, p. 201). It requires skills of communication, recognising and managing emotions, and respecting the child's agency (Winter, 2011).

Yet, as indicated earlier, the child will present with cognitive and emotional characteristics that are shaped indelibly by habitus. It is not that his inner world is only a product of psycho-biographical influences (such as insecure attachments) and life-cycle transitions: it also a matter of wider, societal and cultural conditioning (Robinson, 2007). It is axiomatic that children are socialized by families, peer groups and institutions and by way of their class and ethnic positions (Connolly et al., 2009). This can result in a habitus which privileges education as a route to a better future. Inspirational teachers, in the child's meso-system, 
might have inculcated deep rooted messages about the need for academic success. Yet, the converse might equally be true.

Relatedly, ethno-religious environments imprint a way of being and set of mental habits which can have definitive effects on social and emotional development by, for example, restricting the range of fields a young person can enter. By incorporating a cross-cultural, ecological perspective, social workers can gain greater insights into diverse upbringings (Robinson, 2007). The same argument applies to the child's caregiver. For example, discourses of mothering (Smith, 2012), in contemporary neo-liberal society, present unique demands on caregivers, as mothering comes under increasing public scrutiny. Expert advice about how to carry out the role seeps into consciousness and is an ever present background noise defining normative expectations of care. Such expectations of caregiving become even harder because of demands within the workplace (the exo-system), and changes within the family (the micro-system).

In each of these contexts, social workers can form hypotheses about habitus through deep, phenomenological listening to children and their family members, observation of them in their environments (or fields), assessing their resource allocation (or accumulation of material, cultural and symbolic capital) and, crucially, understanding the impact of the neoliberal, political field on life opportunities. In this undertaking, core assessment skills of communication, observation, reflection and evaluation are required (Coulshed and Orme, 2006). For Garrett (2013(a), p. 42), Bourdieu implores us to engage in 'active and methodical listening as opposed to half understanding based on a distracted and routinized attention'. In all of this, social workers must challenge their own normative assumptions about parenting, significant harm, child development and progression through the life-course. In this regard, Bourdieu called for a 'disruptive, insistent interrogation of established truths' (Garrett, 2013(a), p. 43). This is to embrace a debunking frame of mind and requires that taken-for-granted shibboleths are reviewed critically.

Crucially, this critical examination must extend to the political field - the site of neo-liberal policy where, as Rose (1989, p. 121) contends, 'childhood is the most intensively governed sector of personal existence'. Bourdieu critiqued the economic and political doctrines of neo-liberalism for undermining the State and effecting an unbridled form of de-regulated capitalism. As Garrett (2013(a) and (b)) reminds us, Bourdieu had waged war on the 'scourge of neo-liberalism'. As the State, and its welfare arm, truncate under neo-liberalism, there is less economic capital for communities, less provision for family support, fewer diversionary schemes for young people, a reduced stream of infrastructural support for early years provision and a diminution of universal prevention. Within this shrinking context, social workers need to be sensitized to the fact that fields for children and young people decrease in range, capital becomes much harder to accrue, and the social glue of community loses it binding force. 
Social workers might also appraise, as part of their assessment, the impact of demand characteristics on development. In effect, how have visible, personal and social characteristics, such as age, race, and gender, shaped how others have reacted to the child and parent and influenced their sense of identity? Moreover, how have such reactions determined developmental outcomes? We might respond in a more informed way to such questions if we bring in Bourdieu's notion of the 'field'. The point is that these demand characteristics will have different implications depending on the field in which the child is engaged. A peer group field, with like-minded compatriots, might take these characteristics for granted (as they define an in-group identity) (Jenkins, 2014) whereas an educational field, involving adult teachers from a different background, might possibly respond with predetermined assumptions about character or pre-formed expectations about ability.

Furthermore, when it comes to an assessment of the social context surrounding the child, social workers can make use of Bronfenbrenner's model to probe the influence of the child's micro and meso-systems. They can ascertain their range and size; geographical concentration or dispersal; openness and accessibility; density and connectedness; degree of clustering and level of homogeneity (as regards sharing similar values, needs and interests). Moreover, they can ask questions about levels of intimacy, frequency of contact within the system, whether relationships are symmetrical or not, and whether contacts are routine, episodic or crisis-oriented. Answers to these questions will have a direct bearing on developmental outcomes.

What is more, social workers can assess levels and kinds of social support within these systems: emotional, practical and informational. They can check whether communication is bi-directional and supportive or critical. Social network maps (Dolan et al., 2006), eco-maps (Sudbery, 2010), and genograms (Coulshed and Orme, 2006) are useful tools when it comes to applying Bronfenbrenner's systems to a family's situation. But we can add to this inquiry by importing Bourdieu's idea of capital. This needs to take account of the presence, or absence of material, social and cultural capital within these systems, how the capital is used to progress the child's development, and how capital is linked to the various fields in which the family members are socially positioned. A paucity of material capital, such poor housing and limited income, can impact deleterious on many aspects of life (Wilkinson and Pickett, 2010).

When it comes to an assessment of the child's force characteristics (their persistence and motivation to achieve goals), social workers can review and problematize this area from the standpoint of human agency. According to Bourdieu, agency is indelibly linked to the subtle interplay between habitus, field and capital. Motivation, as such, may not be a fixed inner trait but rather a moving disposition depending on the position occupied by the child in any one field and the capital available to her. It is interesting that Bourdieu recasts agency as a kind of strategizing: a way of maximizing one's purposes by drawing on capital, knowing the field's logics, considering the implications of one's actions and making an informed move. 
The issue is how children and young people are impeded and enabled in this process - and how they come to learn the field's rules. Might it relate, in part, to a habitus infused with a sense of learned helplessness, a sense that one cannot control events based on past experiences? Or, that they a prevented from participating in decision-making affecting them (Thomas, 2009)? From an assessment point of view, we need to know how the social world helps or hinders the development of childhood agency (Winter, 2011). The 'ppct' model will throw up some clues but a deeper take on aetiology might arrive from a conceptual awareness of agency, power and structure.

Finally, the adoption of these two theoretical approaches negates the tendency to privilege developmental psychology, as if it were the premier knowledge-base for explaining child development in social work (Taylor, 2004). In this context, we need to heed Munro's (2002) salutary warning that child and family social workers prefer psychological over social explanations when attempting to understand complex family situations. What is more, the former source has gained added currency within the profession because of the increasing support for evidence-based practice (Mathews and Crawford, 2011). However, an unconsidered appropriation of developmental psychology can lead to sweeping, universalist claims founded on an 'age and stage' model of child maturation (Burman, 1994). Moreover, it can promulgate a view of children as 'becomings' rather than established 'beings' (James and James, 2004); a notion of children entering the world as a 'tabula rasa' (a blank canvass upon which adults 'paint by numbers') (Jenks, 2005); a perspective on childhood that encourages lengthy dependence on caregivers as opposed to acknowledging children's agency (Burman, 1994); and a fixation with psychometric testing, measurement, concepts of deficiency, normality and abnormality (Green, 2010). In all of this, childhood has become an intensively governed domain by the so called 'psy' professionals (for example, psychologists, psychiatrists and social workers) (Rose, 1991; Healy, 2005). What is taken-for-granted as the 'normative' standard then elides into an authoritative benchmark.

In spite of its dominance, though, the critique of this epistemological position has been well rehearsed (Robinson, 2007). Primarily, it fails to locate children within their cultural and historical context. If appropriated uncritically by social workers, the Eurocentric (and ethnocentric) premises that underpin (a crude application of) traditional developmental psychology can lead to oppressive practice when it comes to dealing with families whose backgrounds are ethnically and culturally diverse. It can mean that social workers disregard the uniqueness of a parent or child's habitus and how this is a product of different fields and access to cultural capital. This myopia obscures the legal injunction within the Children Act (Department of Health, 1989, Section 22) to take account of 'the child's religious persuasion, racial origin and cultural and linguistic background'. Cross-cultural competence in social work demands that we reframe 'our practice as contextual, working with environments rather than working despite environments...creating microclimates within broader contexts' (Fook, 2002, p. 162). Contextual awareness is generated not only by applying Bronfenbrenner's PCCT model but also Bourdieu's theorem of agency and structure. By 
adhering to these sources, social workers can ensure that the missing side of the Department of Health triangle (referred to earlier) - dealing with environmental factors - is properly reinstated in social work assessment (Jack and Gill, 2003).

\section{Conclusion}

One can view a child's development through Bronfenbrenner's schematic lens and gain many important insights around the interplay between the biological, psychological and social domains of influence. One can then enrich this understanding by switching to a Bourdieusian perspective with its sociological insights into how certain children keep winning while others keep losing - as a consequence of social reproduction. This combined two-eyed approach can give a 'comparative purchase on the sometimes bewildering complexities, challenges, and difficulties, seemingly so very idiosyncratic, of the cases that they (social workers) seek to tackle' (Emirbayer and Williams, 2005, p. 718). In this paper, I have argued that Bronfenbrenner's perspicacious model of child development can be complemented by Bourdieu's critical theory of agency, power and structure - even though they are distinctly different theories. The former brings conceptual clarity concerning the interplay between the person and her social context and how it shapes developmental attainments throughout the life-course. Yet, it lacks a critical edge. The analytical constructs of habitus, field and capital compensate, to some degree, this inadequacy, enabling social workers to assess children and their families as socially positioned actors operating within a politicized context.

Social workers must also cast a critical, reflexive gaze over their own profession for, it too, is positioned in a welfare field that is insuperably shaped by an overarching, neo-liberal, political one (Garrett, 2009). Crucially, social workers must begin to reflexively analyse (through supervision and other enabling mediums) their own habitus, how it is constrained (and enabled) by this undergirding political field, and the capital it generates (Winter, 2011). Moreover, they use (what Bourdieu refers to as) doxic knowledge: suppositions that are taken-for-granted, whether drawn from the social sciences, practice theory or from the law (Garrett, 2013(a)). In what way does such knowledge reproduce relations of power? They must further ask whether the practice of social work accentuates the capital possessed by families so that they can provide optimal care for their children? Or, in what ways does it dispossess individuals, disenfranchising them through the medium of symbolic violence - a medium that perpetuates the discourses of the dominant? Reflexive questions such as these move us in the direction of a critical ecology of child development. 


\section{References}

Aldgate, J, Jones, D, Rose, W and Jeffrey, C, 2006, The developing world of the child, London: Jessica Kingsley.

Besthorn, F, 2013, Ecological approach, in M. Gray and S. Webb (eds) ( $2^{\text {nd }}$ ed.) Social work theories and methods, London: Sage, 173-182.

Bourdieu, P, 1991, Language and symbolic power, Cambridge: Polity Press.

Bourdieu, P, 2003, Outline of a theory of practice, Cambridge: Cambridge University Press.

Branch, S, Homel, R, and Freiberg, K, 2013, Making the developmental system work better for children: Lessons learned implementing an innovative programme, Child and Family Social Work, 18, 294-304.

Bronfenbrenner, U, 1979, The ecology of human development: Experiments in nature and design, Cambridge: Harvard University Press.

Bronfenbrenner, U, 2005, Making human beings human: Bio-ecological perspectives on human development, London: Sage

Burman, E, 1994, Deconstructing developmental psychology, London: Routledge.

Connolly, P, 2004, Boys and schooling in the early years, London: Routledge Farmer.

Connolly, P, Kelly, B and Smith, A, 2009, Ethnic habitus and young children: A case study in Northern Ireland, European Early Childhood Education Research Journal, 17(2), 217-232.

Coulshed, V, 1988, Social work practice - An introduction, Basingstoke: Macmillan.

Coulshed, V and Orme, J, 2006, Social work practice ( $4^{\text {th }}$ ed.), Basingstoke: Palgrave Macmillan.

Department of Health, 2000, Framework for the Assessment of Children in Need and Their Families, London: The Stationery Office.

Dolan, P, Pinkerton, J and Canavan, J, 2006, Family support as reflective practice, London: Jessica Kingsley.

Emirbayer, M and Williams, E, 2005, Bourdieu and social work, Social Service Review, 4, 689724.

Fook, J, 2002, Social work: Critical theory and practice, London: Sage.

Fowler, B, 1997, Pierre Bourdieu and cultural theory: Critical investigations, London: Sage. 
Garrett, P, M, 2009, Transforming children's services? Social work, neoliberalism and the modern world, Maidenhead: OU Press.

Garrett, P, M, 2013 (a), Pierre Bourdieu, in M. Gray and S. Webb (eds.) Social Work Theories and Methods ( $2^{\text {nd }}$ ed.), London: Sage.

Garrett, P,M, 2013 (b), Social Work and Social Theory: Making Connections, Bristol: Policy Press.

Green, L, 2010, Understanding the life course: Sociological and psychological perspectives, Cambridge: Polity.

Hardy, F and Darlington, Y, 2008, What parents value from formal support services in the context of identified child abuse, Child and Family Social Work, 13, 252-261.

Harney, P, 2007, Resilience processes in context, Journal of Aggression Maltreatment and Trauma, 14(3), 73-87.

Healy, K, 2005, Social work theories in context: Creating frameworks for practice, Basingstoke: Palgrave Macmillan.

Holland, S, 2010, Child and family assessment in social work practice ( $2^{\text {nd }}$ ed.), London: Sage. Horwath, J, (ed.), 2010, The child's world: The comprehensive guide to assessing children in need, London: Jessica Kingsley.

Houston, S, 2002, Reflecting on habitus, field and capital, Journal of Social Work, 2(2), 149167.

Jack, G, 2010, 'Ecological influences on parenting and child development', British Journal of Social Work, 30, 703-20.

Jack, G and Gill, O, 2003, The missing side of the triangle, London: Barnardo's.

James, A and James, A, 2004, Constructing childhood: Theory, policy and social practice, Basingstoke: Palgrave Macmillan.

Jenkins, S, 2014, Social identity ( $4^{\text {th }}$ ed.), London: Routledge.

Jenks, C, 2005, Childhood ( $2^{\text {nd }}$ ed.), London: Routledge.

Mathews, I and Crawford, K, (eds.), 2011), Evidence-based practice in social work, Exeter: Learning Matters.

Munro, E, 2002, Effective child protection, London: Sage.

Munro, E, 2010, The Munro review of child protection. Part One: a system analysis, London: Department for Education. 
Payne, C,M, 2008, So much reform, so little change: The persistence of failure in urban schools, Cambridge: Harvard Education Press.

Peillon, M, 1998, 'Bourdieu's field and the sociology of welfare, Journal of Social Policy, 27 (2), 213-29.

Reder, P and Duncan, S, 2004, 'Making the most of the Victoria Climbié Inquiry Report', Child Abuse Review, 13, 95-114.

Robinson, L, 2007, Cross-cultural child development for social workers: An introduction, Basingstoke: Palgrave Macmillan.

Rose, N, 1989, Governing the soul: The shaping of the private self, London: Routledge.

Santrock, J, 2009, Life span development, Boston: McGraw Hill.

Serbati, S., Pivetti, M and Gioga, G, 2013, Child well-being scales (CWBS) in the assessment of families and children in home-care intervention, Child and Family Social Work, September 2013 (advanced access).

Smith, L, 2012, The demands of motherhood: Agents, roles and recognition, Basingstoke: Palgrave Macmillan.

Sudbery, J, 2010, Human growth and development: An introduction for social workers, London: Routledge.

Taylor, C, 2004, Underpinning knowledge for child care practice: reconsidering child development theory, Child and Family Social Work, 9, 225-235.

Tew, J, 2006, Understanding power and powerlessness: Towards a framework for emancipatory practice in social work, Journal of Social Work, 6(1), 33-57.

Thomas, N, 2009, (ed.), Children, politics and communication: Participation at the margins.

Trevithick, P, 2009, Social work skills: A practice handbook, Maidenhead: Open University Press.

Tudge, J, Mokrova, I, Hatfield, B and Karnik, R, 2009, Uses and misuses of Bronfenbrenner's bio-ecological theory of human development, Journal of Family Theory and Review, 1, 198210.

Turney, D, Platt, D, Selwyn, J and Farmer, E, 2012, Improving child and family assessments: Turning research into practice, London: Jessica Kingsley.

Wilkinson, R and Pickett, K, 2010, The spirit level: Why equality is better for everyone, London: Penguin. 
Winter, K, 2011, Building relationships and communication with young children: A practical guide for social workers, London: Routledge. 